УДК 796.3: 005

DOI https://doi.org/10.26661/2663-5925-2021-2-04

\title{
ЗМІНИ ІНДЕКСІВ ФІЗИЧНОГО РОЗВИТКУ СТУДЕНТІВ ЗА ПІДСУМКАМИ РЕАЛІЗАЦІЇ ІНДИВІДУАЛЬНО-МОТИВАЦІЙНИХ РІВНІВ СИСТЕМИ НАВЧАННЯ ПЛАВАННЯ
}

\author{
Глухов I. Г. \\ кандидат педагогічних наук, дочент \\ Херсонський державний університет \\ вул. Університетська, 27, Херсон, Україна \\ orcid.org/0000-0003-4226-5253 \\ swim.ks.ua@gmail.com \\ Пітин М. П. \\ доктор фізичного виховання і спорту, професор \\ Львівський державний університет фізичної культури \\ імені Івана Боберського \\ вул. Костюшка, 11, м. Львів, Украӥна \\ orcid.org/0000-0002-3537-4745 \\ pityn7@gmail.com
}

\begin{abstract}
Ключові слова:
система, плавання, рівні, ефективність, індекси.
\end{abstract}

\begin{abstract}
Зважаючи на чіткі пріоритети, покладені в основу процесу фізичного виховання студентської молоді, обов'язковим є опанування ними системи прикладних умінь та навичок. Мета дослідження - установити зміни індексів фізичного розвитку студентів закладів вищої освіти за підсумками реалізації програм занять на різних індивідуально-мотиваційних рівнях системи навчання плавання. Матеріал і методи. Учасники дослідження. До дослідження було залучено студентів (юнаки та дівчата) 18-20 років, що навчалися в Херсонському державному університеті впродовж 20202021 навчального року. Контингент студентів такий: 1 експериментальна група $-\mathrm{n}=28$ юнаків та 23 дівчини; 2 експериментальна група n = 25 юнаків та 26 дівчат; 3 експериментальна група $-\mathrm{n}=21$ юнаків та 23 дівчини; 4 експериментальна група - n = 23 юнака та 21 дівчина; контрольна група $-\mathrm{n}=32$ юнаки та 29 дівчат. Результати. Для різних індивідуально-мотиваційних рівнів системи навчання плавання студентів закладів вищої освіти є різна структура функціональної підготовленості юнаків та дівчат, що визначається їхнім попереднім руховим досвідом, безпосередніми показниками фізичного розвитку, за наявності об’ єднавчого чинника - рівня володіння руховими уміннями із плавання. Ефективність застосування програм занять на різних індивідуально-мотиваційних рівнях системи навчання плавання студентів закладів вищої освіти визначається статистично вірогідними змінами внутрішньогрупових показників як серед юнаків, так і серед дівчат за показниками швидкісного, швидкісносилового та силового індексів $(1,00-9,43 \%, \mathrm{p} \leq 0,05-0,01)$. Результати на внутрішньогруповому рівні довели здебільшого статистично вірогідні переваги юнаків та дівчат четвертого індивідуально-мотиваційного рівня надіншими групами в кінці дослідження. Висновки. Виявлена ефективність програм занять за показниками індексів фізичної підготовленості в межах системи навчання плавання студентів у фізичному вихованні закладів вищої освіти здебільшого не стільки пов'язана зі специфікою використаних засобів, скільки є результатом систематичних та цілеспрямованих впливів на функціональний та фізичних стан студентів, що покладено в основу змісту розвивальних впливів та базових завдань фізичного виховання у виші, зокрема й реалізації системи навчання плавання.
\end{abstract}




\title{
CHANGES IN INDICES OF STUDENTS' PHYSICAL DEVELOPMENT AS A RESULT OF IMPLEMENTATION OF INDIVIDUAL AND MOTIVATIONAL LEVELS OF THE SWIMMING TRAINING SYSTEM
}

\author{
Hluhov I. H. \\ Ph. D. (Pedagogical Sciences), Associate Professor \\ Kherson State University \\ University str., 27, Kherson, Ukraine \\ orcid.org/0000-0003-4226-5253 \\ swim.ks.ua@gmail.com
}

Pityn M. P.

DSc. (Physical Education and Sports), Professor

Lviv State University of Physical Culture named after Ivan Bobersky

Kosciuszko str., 11, Lviv, Ukraine

orcid.org/0000-0002-3537-4745

pityn7@gmail.com

Key words: system, swimming, levels, efficiency, indices.
Paying attention to the clear priorities underlying the process of physical education of student youth, it is mandatory for them to master the system of applied skills. The purpose of the study - to establish changes in the indices of physical development of higher educational institutions students based on the results of the implementation of training programs at different individual and motivational levels of the swimming training system. Material and methods. Study participants. To the study involved students (boys and girls) aged 18-20 years old, who studied at Kherson State University during 20202021 academic year. The contingent of students was: $1 E G, n=28$ boys and 23 girls; $2 \mathrm{EG}, \mathrm{n}=25$ boys and 26 girls; $3 \mathrm{EG}, \mathrm{n}=21$ boys and 23 girls; 4EG, $\mathrm{n}=23$ boys and 21 girls; $C G, \mathrm{n}=32$ boys and 29 girls. Results. For different individual and motivational levels of the system of swimming training system students of higher educational institutions is available different structure of functional preparedness of boys and girls, which is determined by their previous motor experience, direct indicators of physical development at the unifying factor - a certain level of swimming skills. The effectiveness of the application training programs at different individual and motivational levels of the swimming training system for students of higher educational institutions is determined by statistically significant changes in intragroup indicators among boys and girls according to speed, speed and power and power indices $(1,00-9,43 \%, p \leq 0,05-0,01)$. Conclusions. The identified effectiveness of training programs on the indicators of physical fitness indices within the swimming training system for students in physical education of higher educational institutions is not so much related to the specifics of the means used, but is the result of systematic and targeted effects on functional and physical condition of students. This is the basis task of physical education of higher educational institutions, including realization of swimming training system.
Постановка проблеми й аналіз основних досліджень. Зважаючи на чіткі пріоритети, покладені в основі процесу фізичного виховання студентської молоді, обов' язковим є опанування ними системи прикладних умінь та навичок $[2 ; 4 ; 5 ; 8]$. Достовірність отримання результатів наукових досліджень значною мірою визначається рівнем адекватності підбору та комплексністю застосування методів та засобів, що забезпечують педагогічні впливи на організм студентів $[1 ; 6 ; 7 ; 9 ; 12]$.
Наявнінаукові данівідображаютьнауково-практичні завдання, спрямовані на загальні підходи навчання плавання - випереджувальне та пришвидшене навчання плавання, методики подолання студентами водобоязні, застосування рухливих ігор, варіативності засобів плавальної підготовки студентів, окремі аспекти організації навчання плавання у фізичному вихованні $[10 ; 11 ; 13-16]$.

Наукове обгрунтування структури та змісту фізичного виховання на основі засобів плавання 
варто проводити 3 урахуванням об'єктивних показників фізичного розвитку, підвищення функціональних можливостей, плавальної підготовленості тощо.

Зв'язок роботи 3 науковими темами та планами. Дослідження виконане згідно 3 темою 3.3. «Теоретико-методичні аспекти оптимізації рухової активності різних груп населення» зведеного плану науково-дослідної роботи Львівського державного університету фізичної культури на 2017-2020 рр., теми «Теоретичні і методичні основи навчання плавання різних груп населення» плану науково-дослідної роботи Херсонського державного університету на 2021-2026 pр.

Мета дослідження - установити зміни індексів фізичного розвитку студентів ЗВО за підсумками реалізації програм занять на різних індивідуально-мотиваційних рівнях системи навчання плавання.

Матеріал і методи. Учасники дослідження. До дослідження було залучено студентів (юнаки та дівчата) 18-20 років, що навчалися в Херсонському державному університеті, які упродовж 2020-2021 навчального року обрали як основний зміст занять із фізичного виховання плавання. Вони були віднесені до експериментальних груп, що займалися плаванням на чотирьох індивідуально-мотиваційних рівнях системи навчання плавання. Для першого індивідуально-мотиваційного рівня характерною відмінністю було те, що студенти мають великий рівень страху щодо перебування у воді та не вміють плавати (1 експериментальна група (далі - ЕГ), кількість студентів становила 28 юнаків та 23 дівчини). Другий індивідуально-мотиваційний рівень представлений студентами, які мають незначний рівень страху щодо перебування у воді, проте не вміли плавати (2ЕГ, n = 25 юнаків та 26 дівчат). Для третього індивідуально-мотиваційного рівня характерним було те, що студенти мали вміння/навички тримання на воді, плавали довільним способом (3ЕГ, $\mathrm{n}=21$ юнак і 23 дівчини). До четвертого індивідуально-мотиваційного рівня віднесено студентів, які володіють уміннями та навичками із плавання та мали бажання займатись i вдосконалювати техніку надалі (4ЕГ, $\mathrm{n}=23$ юнаки та 21 дівчина). До складу контрольної групи (далі - КГ) належали студенти, які займалися у загальних групах із фізичного виховання (КГ, $\mathrm{n}=32$ юнаки та 29 дівчат) [2; 3].

Організачія дослідження. Усі програми (експериментальні та контрольна) були розраховані на 18 занять упродовж першого навчального семестру. Така особливість визначена відповідно до мінімальних нормативних вимог щодо фізичного виховання в Херсонському державному університеті та можливостей індивідуальної траєкторії навчання студентів. Тривалість занять становила 60 хвилин.

Статистичний аналіз. Проводили розрахунки головних одномірних статистик: середнього арифметичного - $\bar{X}$, стандартної помилки середнього - m; t-критерію Стьюдента - для встановлення відмінностей між двома вибірками за базовий приймали 5\% рівень статистичної вірогідності - р (вірогідність не менша 0,95); під час аналізу результатів усередині кожної вибірки використовували значення $\mathrm{t}$ для порівняння результатів зв'язаних вибірок, різних груп - для непов'язаних вибірок.

Результати дослідження та їх обговорення. Цінність зазначених показників швидкісного, швидкісно-силового та силового індексів виявляється в можливості зіставлення двох параметрів, які підсилюють розуміння загального рівня готовності та функціональних можливостей організму студентів (табл. 1 та 2) [1; 5-7].

У межах аналізування швидкісного індексу, що передбачав зіставлення швидкості подолання відтинку 100 м та довжини тіла студентів, виявлено, що на початковому етапі педагогічного експерименту статистично вірогідних відмінностей між представниками різних експериментальних груп не було [7]. Діапазон відмінностей перебував у межах від 0,26 до 1,75\% (p>0,05) на користь тієї чи іншої ЕГ. У зіставленні показників швидкісного індексу студентів експериментальних та контрольної групи на вихідному етапі статистично вірогідні відмінності були зафіксовані лише щодо представників 3ЕГ. Вони переважали студентів КГ на $3,77 \%(\mathrm{p} \leq 0,05)$.

За час педагогічного експерименту зафіксовано, що, незважаючи на спрямованість засобів, спрямованість структури та змісту програм занять, представникам усіх залучених до дослідження груп студентів вдалося статистично вірогідно покращити значення цього індексу на внутрішньогруповому рівні. Вищі показники відносного приросту швидкісного індексу встановлені для студентів $3 \mathrm{EГ}(1,34 \%, \mathrm{p} \leq 0,05)$. Для кількох груп (2ЕГ, 4ЕГ та КГ) показники покращення становили $1,15-1,20 \%(\mathrm{p} \leq 0,05)$, найнижчі прирости показали студенти $1 \mathrm{EГ}(0,80 \%, \mathrm{p} \leq 0,05)$.

Під час зіставлення підсумкових результатів на міжгруповому рівні спостерігалася та ж ситуація, що і на вихідному педагогічному спостереженні. Лише в одному випадку, між студентами 3ЕГ та КГ, були виявлені достовірні відмінності, які внаслідок реалізації програм занять дещо збільшилися до $3,97 \%(\mathrm{p} \leq 0,05)$. Уважаємо, що виявлена ефективність програм занять у межах фізичного виховання не стільки пов'язана зі специфікою використаних засобів, скільки є результатом систематичних та цілеспрямованих впливів 
на функціональний та фізичних стан студентів, що покладено в основу фізичного виховання ЗВО.

Схожа ситуація спостерігалася для даних швидкісно-силового індексу. На початковому етапі педагогічного експерименту між представниками більшості груп також не було виявлено статистично вірогідних відмінностей. Перевага студентів тієї чи іншої групи коливалася в незначних межах $(\mathrm{p}>0,05)$ та становила від 1,09 до 4,28\%. Лише в одному з випадків, на вихідному педагогічному спостереженні представники 4ЕГ достовірно переважали студентів КГ. Відмінності становили 4,31\% за $\mathrm{p} \leq 0,05$. Уважаємо, що це може бути зумовлене певною структурою групи студентів та їхніми індивідуальними особливостями у складниках цього індексу.

Цінною $\epsilon$ інформація, що вказала нам на статистично вірогідне покращення показників швидкісно-силового індексу студентів експериментальних груп. Засвідчено, що незалежно від індивідуально-мотиваційного рівня програми занять дали позитивний ефект. Так, студентам $3 Е Г$ вдалося покращити його на $2,40 \%(\mathrm{p} \leq 0,01)$, а представникам 1ЕГ, 2ЕГ та 4ЕГ на $1,30-1,82 \%$ $(\mathrm{p} \leq 0,05)$. Студенти КГ незначно покращили результати за швидкісно-силовим індексом, а відсоткова зміна значень становила $0,75 \%(\mathrm{p}>0,05)$. Це доводить виражену ефективність запропонованої системи навчання плавання для підвищення функціональних показників студентів у частині швидкісно-силових якостей.

Згідно з результатами аналізу даних силового індексу можемо стверджувати про здебільшого середній та нижче середнього рівні показників. Результати всіх студентів на вихідному етапі дослідження коливалися в межах 43,60-49,19 ум. од. Співвідношення показників різних груп студентів, залучених до педагогічного експерименту, дало змогу констатувати відсутність значної кількості статистично вірогідних відмінностей $(\mathrm{p}>0,05)$, а самі значення становили 0,15-9,52\% на користь тієї чи іншої групи студентів. Лише у двох випадках, на початку дослідження зафіксовано достовірні відмінності. У цих випадках представники 2 ЕГ поступалися студентам 4ЕГ $(12,80 \%, \mathrm{p} \leq 0,05)$ i 1 ЕГ $(8,83 \%, \mathrm{p} \leq 0,05)$. Уважаємо, що ці відмінності пов'язані із природним підбором студентів, залучених до відповідних груп.

У процесі дослідження встановлено цінну інформацію, згідно 3 якою за підсумками реалі-

Таблиця 1

Зміни показників фізичного розвитку та функціональної підготовленості студентів на різних індивідуально-мотиваційних рівнях системи навчання плавання в межах фізичного виховання 3ВО

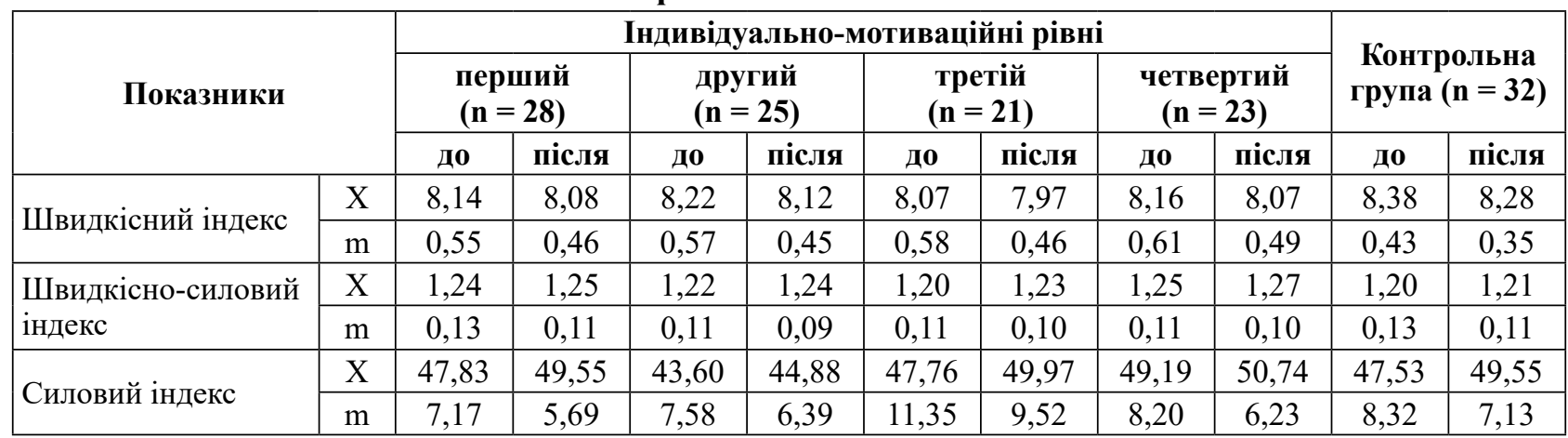

Таблиця 2

Зміни показників фізичного розвитку та функціональної підготовленості студенток на різних індивідуально-мотиваційних рівнях системи навчання плавання в межах фізичного виховання 3ВО

\begin{tabular}{|c|c|c|c|c|c|c|c|c|c|c|c|}
\hline \multirow{3}{*}{\multicolumn{2}{|c|}{ Показники }} & \multicolumn{8}{|c|}{ Індивідуально-мотиваційні рівні } & \multirow{2}{*}{\multicolumn{2}{|c|}{$\begin{array}{c}\text { Контрольна } \\
\text { група }(\mathrm{n}=29)\end{array}$}} \\
\hline & & \multicolumn{2}{|c|}{$\begin{array}{c}\text { перший } \\
(\mathbf{n}=\mathbf{2 3})\end{array}$} & \multicolumn{2}{|c|}{$\begin{array}{l}\text { другий } \\
(\mathbf{n}=\mathbf{2 6}) \\
\end{array}$} & \multicolumn{2}{|c|}{$\begin{array}{c}\text { третій } \\
(\mathbf{n}=\mathbf{2 3})\end{array}$} & \multicolumn{2}{|c|}{$\begin{array}{l}\text { четвертий } \\
(\mathrm{n}=\mathbf{2 1})\end{array}$} & & \\
\hline & & до & після & до & після & до & після & до & після & до & після \\
\hline \multirow{2}{*}{ Швидкісний індекс } & $\mathbf{X}$ & 9,45 & $\mathbf{9 , 3 5}$ & 9,60 & $\mathbf{9 , 4 4}$ & 9,36 & $\mathbf{9 , 2 3}$ & $\mathbf{9 , 4 4}$ & $\mathbf{9 , 2 9}$ & 9,71 & $\mathbf{9 , 5 8}$ \\
\hline & $\mathrm{m}$ & 0,59 & 0,58 & 0,69 & 0,59 & 0,53 & 0,46 & 0,68 & 0,58 & 0,59 & 0,54 \\
\hline \multirow{2}{*}{$\begin{array}{l}\text { Швидкісно-силовий } \\
\text { індекс }\end{array}$} & $\mathrm{X}$ & 1,02 & 1,04 & 1,01 & 1,03 & 1,02 & 1,04 & 1,02 & 1,05 & 1,01 & 1,02 \\
\hline & $\mathrm{m}$ & 0,04 & 0,04 & 0,05 & 0,04 & 0,04 & 0,04 & 0,03 & 0,04 & 0,04 & 0,04 \\
\hline \multirow{2}{*}{ Силовий індекс } & $\mathrm{X}$ & 44,45 & 47,23 & 40,69 & 44,52 & 47,68 & 50,82 & 47,91 & 50,99 & 48,14 & 49,53 \\
\hline & $\mathrm{m}$ & 8,78 & 6,79 & 8,28 & 5,98 & 6,76 & 5,75 & 7,91 & 6,14 & 8,32 & 7,08 \\
\hline
\end{tabular}


зації педагогічного експерименту на внутрішньогруповому рівні представники всіх груп студентів покращили значення силового індексу. Покращення становило від 2,92 до 4,65\% $(\mathrm{p} \leq 0,05)$ для представників ЕГ та 4,24\% (p $\leq 0,05)$ - студентів КГ.

Такі внутрішньогрупові зміни дали змогу незначно змінити структуру відмінностей між студентами експериментальних та контрольних груп. Після завершення дослідження ми спостерігали посилення відмінностей між представниками $1 \mathrm{E} Г$ та $2 \mathrm{E} Г$ до $12,00 \%(\mathrm{p} \leq 0,05), 2 \mathrm{E} \Gamma$ та $4 \mathrm{EГ} \mathrm{-} \mathrm{до} \mathrm{13,06} \mathrm{(} \leq 00,05)$, формування переваги КГ над представниками $2 \mathrm{E}(10,41 \%, p \leq 0,05)$. Отже, можна об'єктивно засвідчити необхідність звернення уваги на певну орієнтацію змісту програми занять на другому індивідуально-мотиваційному рівні до необхідності підвищення силових можливостей м'язів нижніх кінцівок студентів.

Зважаючи на універсальність науково-методичного підходу, запропонованого для побудови системи навчання плавання студентів 3ВО, та наявність різних гендерних груп, ми провели аналогічне вивчення показників фізичного розвитку та функціональних можливостей студенток (табл. 2). Вони були також диференційовані за різними індивідуально-мотиваційними рівнями системи навчання плавання студентів ЗВО у межах фізичного виховання [3].

Під час аналізування швидкісного індексу ми встановили, що на початковому етапі дослідження діапазон відмінностей перебував у межах від 0,04 до $2,87 \%(p>0,05)$ на користь тієї чи іншої групи студенток. Виняток становили лише значення представниць $3 Е Г$, які статистично вірогідно переважали студенток КГ на 3,71\% $(\mathrm{p}=0,03)$.

Цінною $\epsilon$ інформація, що за час педагогічного експерименту, незважаючи на спрямованість використаних засобів для програм занять, представникам усіх залучених до дослідження груп студенток вдалося статистично вірогідно покращити значення цього індексу на внутрішньогруповому рівні. Вищі показники відносного приросту швидкісного індексу встановлені для студенток 4ЕГ $(1,65 \%, \mathrm{p} \leq 0,01)$. Для кількох груп (2ЕГ, 4ЕГ та КГ) показники покращення становили $1,00-1,48 \%(\mathrm{p} \leq 0,05)$, для представниць КГ $-1,32 \%(\mathrm{p} \leq 0,01)$. Зіставлення підсумкових результатів на міжгруповому рівні засвдчило таку саму ситуацію, що і на вихідному педагогічному тестуванні. Статистично вірогідно студентки ЗЕГ переважали за середньогруповими значеннями студенток КГ $(3,89 \%, \mathrm{p}=0,01)$.

Схожа ситуація спостерігалася для результатів швидкісно-силового індексу дівчат ЕГ і КГ. На початковому етапі між представниками більшості груп не було виявлено статистично вірогідних відмінностей $(p>0,05)$. Перевага представ- ниць тієї чи іншої групи становила від 0,07 до $2,12 \%$. За підсумками реалізації програм занять різного методичного змісту зафіксоване загальне та статистично вірогідне покращення показників швидкісно-силового індексу студенток усіх експериментальних та контрольної груп. Засвідчено, що незалежно від індивідуально-мотиваційного рівня програми занять дали позитивний ефект ( $\mathrm{p} \leq 0,01$ для всіх представлених груп). Водночас відносні значення покращення мали відмінності. Вищі прирости спостерігалися у представниць 4ЕГ (3,14\% від вихідного рівня), а для решти ЕГ значення покращення становили $1,83-1,93$, КГ $1,41 \%$ від вихідного рівня.

Отримані результати на внутрішньогруповому рівні дали підстави спостерігати утворення однієі статистично вірогідної відмінності, а саме переваги представниць 4ЕГ над КГ у кінці педагогічного експерименту $(2,46 \%, p=0,02)$. Це свідчить про достовірні відмінності ефективності методичної компоненти змісту програм занять у межах фізичного виховання ЕГ на цьому індивідуально-мотиваційному рівні та КГ за цим показником.

За показниками силового індексу дівчат, залучених до дослідження, встановлено загалом незадовільний загальний рівень результатів (40,69-48,14 ум. од.). У трьох випадках, на початку дослідження, зафіксовано достовірні відмінності. Згідно з отриманими даними, представниці 2ЕГ поступалися студентам 4ЕГ $(17,75 \%$, $\mathrm{p} \leq 0,01), 3 \mathrm{E} \Gamma(17,18 \%, \mathrm{p} \leq 0,01)$ та КГ $(18,32 \%$, $\mathrm{p} \leq 0,01)$. У процесі дослідження встановлено, що за підсумками програм занять на внутрішньогруповому рівні представниці всіх груп покращили силовий індекс. Покращення становили від 6,26 до $9,43 \%$ (р $\leq 0,01)$ для представниць ЕГ та 2,89\% $(\mathrm{p}=0,02)$ - студенток КГ. Такі внутрішньогрупові зміни дали змогу незначно змінити значення відмінностей між студентками різних груп за сталого рівня статистичної вірогідності ( $\leq \leq 0,01)$. Так, представниці $2 \mathrm{EГ} \mathrm{за} \mathrm{результатами} \mathrm{педагогічного}$ експерименту зменшили відставання від 4ЕГ до $14,53 \%, 3 \mathrm{E} \Gamma-14,13 \%, \mathrm{KГ}-11,25 \%$.

Висновки. Для різних індивідуально-мотиваційних рівнів системи навчання плавання студентів 3ВО характерна різна структура функціональної підготовленості юнаків та дівчат, що визначається їхнім попереднім руховим досвідом, безпосередніми показниками фізичного розвитку за об'єднавчого чинника - рівня володіння руховими вміннями із плавання.

Ефективність застосування програм занять на різних індивідуально-мотиваційних рівнях системи навчання плавання студентів ЗВО визначається статистично вірогідними змінами внутрішньогрупових показників як серед юнаків, так і серед дівчат за показниками швидкісного, швид- 
кісно-силового та силового індексів (1,00-9,43\%, $\mathrm{p} \leq 0,05-0,01)$.

Виявлена ефективність програм занять за показниками індексів фізичної підготовленості в межах системи навчання плавання студентів у фізичному вихованні ЗВО здебільшого не стільки пов'язана зі специфікою використаних засобів, скільки є результатом систематичних та цілеспрямованих впливів на функціональний та фізичних стан студентів, що покладено в основу змісту розвивальних впливів та базових завдань фізичного виховання 3ВО, зокрема й реалізації системи навчання плавання.

Перспективи подальших досліджень передбачають вивчення змін базових показників функціональної, фізичної та плавальної підготовленості студентів 3ВО за результатами реалізації програм занять системи навчання плавання в межах фізичного виховання.

\section{ЛІТЕРАТУРА}

1. Блавт О. Концептуальні положення організації і формування змісту тестового контролю студентів у фізичному вихованні спеціальних медичних груп. Молодіжний науковий вісник Східноєвропейського наиіонального університету імені Лесі Українки. Луцьк, 2015. № 19. С. 50-55.

2. Теоретичний аналіз проблем та актуальних напрямів навчання студентської молоді плаванню / І. Глухов та ін. Український журнал медицини, біологї̈ та спорту. Миколаїв, 2020. № 5, 4 (26). C. 406-413. DOI: 10.26693/jmbs05.04.406.

3. Глухов І., Пітин М. Система навчання студентів плаванню у фізичному вихованні закладів вищої освіти : перспективи дослідження. Фізична культура, спорт та здоров'я нащії. Вінниця, 2020. № 9 (28). С. 14-20.

4. Гончар И. Теория преподавания плавания: технологии обучения и совершенствования : монография. Одесса : Астропринт, 2005. Ч. 1. 524 с.

5. Журавльов Ю. Динаміка функціональної підготовленості студентів 18-19 років у процесі секційних занять $з$ плавання. Вісник Запорізького національного університету. Серія «Фізичне виховання $i$ cnopm». 2018. № 1. C. 5-11.

6. Іващенко О. Педагогічний контроль рухової і функціональної підготовленості дівчат 15-16 років. Теорія та методика фізичного виховання. 2016. № 3. С. 36-50. DOI: 10.17309/tmfv.2016.3.1171.

7. Круцевич Т., Воробйов М., Безверхня Г. Контроль у фізичному вихованні дітей, підлітків і молоді. Київ : Олімп. л-ра, 2011. 224 с.

8. Сальникова С., Гуренко О., Пуздимір М. Динаміка показників фізичної підготовленості студентів ВНЗ під впливом занять з плавання, легкої атлетики та боксу. Фізична культура, сnорт та здоров'я наиї. Вінниця, 2017. № 4. С. 226-231.

9. Swimming training for asthma in children and adolescents aged 18 years and under / S. Beggs et al. Cochrane Database Syst. Rev. 2013. DOI: 10.1002/14651858.CD009607.pub2.

10. Water-versus land-based exercise in elderly subjects: effects on physical performance and body composition / M. Bergamin et al. Clin. Interv. Aging. 2013. № 8. P. 1109-1117. DOI: 10.2147/ CIA.S44198.

11. The effectiveness of the endogenous-hypoxic breathing in the physical training of skilled swimmers / I. Hruzevych et al. Journal of Physical Education and Sport. 2017. № 17 (3). P. 1009-1016. DOI: 10.7752/ jpes.2017.s3155.

12. Analysis of the indicators of athletes at leading sports schools in swimming / S. Ivanenko et al. Journal of Physical Education and Sport. 2020. № 20 (4). P. 1721-1726. DOI: 10.7752/jpes.2020.04233.

13. The Effect of Swimming Abilityon the Anxiety Levels of Female College Students / T. Muhamad et al. Asian Social Science. 2013. № 9. P. 15.

14. Pashkevich S., Kriventsova I., Galicheva K. Using Movement Test to Evaluate Effectiveness of Health and Fitness Activities of Students in Higher Education Institutions. Teoriâ Ta Metodika Fizičnogo Vihovannâ. 2018. № 18 (1). P. 12-22. DOI: 10.17309/tmfv.2018.1.02.

15. Petrescu S., Pitigoi G., Păunescu M. The Effects of Practicing Swimming on The Psychological Tone in Adulthood, Procedia. Social and Behavioral Sciences. 2014. № 159. P. 74-77.

16. Development of young pupils' physical qualities on the systematic approach basis in the physical education process / O. Shvets et al. SPORT AND SOCIETY Interdisciplinary Journal of Physical Education and Sports. 2020. № 20. P. 2. DOI: 10.36836/2020/2/5. 


\section{REFERENCES}

1. Blavt, O.Z. (2015). Kontseptualni polozhennia orhanizatsii i formuvannia zmistu testovoho kontroliu studentiv u fizychnomu vykhovanni spetsialnykh medychnykh hrup [Conceptual provisions of the organization and formation of the content of test control of students in physical education of special medical groups]. Molodizhnyi naukovyi visnyk Skhidnoievropeiskoho natsionalnoho universytetu imeni Lesi Ukrainky. Lutsk, 19, 50-55. [in Ukrainian]

2. Hlukhov, I.H., Pityn, M.P., Drobot, K.V., \& Abramov, K.V. (2020). Teoretychnyi analiz problem ta aktualnykh napriamiv navchannia studentskoi molodi plavanniu [Theoretical analysis of problems and current areas of teaching student youth swimming]. Ukrainskyi zhurnal medytsyny, biolohii ta sportu. Mykolaiv, 5, 4 (26), 406-413. DOI: 10.26693/jmbs05.04.406 [in Ukrainian].

3. Hlukhov, I., \& Pityn, M. (2020). Systema navchannia studentiv plavanniu u fizychnomu vykhovanni zakladiv vyshchoi osvity : perspektyvy doslidzhennia [The system of teaching students to swim in physical education of higher education institutions: prospects for research]. Fizychna kultura, sport ta zdorovia natsii. Vinnytsia, 9 (28), 14-20. [in Ukrainian]

4. Gonchar, I.L. (2005). Teorija prepodavanija plavanija: tehnologii obuchenija i sovershenstvovanija [Swimming Teaching Theory: Teaching and Improvement Technologies] : monografija. Odessa. Ch. 1, 524. [in Russian]

5. Zhuravlov, Yu.H. (2018). Dynamika funktsionalnoi pidhotovlenosti studentiv 18-19 rokiv v protsesi sektsiinykh zaniat z plavannia [Dynamics of functional readiness of students aged 18-19 in the process of sectional swimming lessons]. Visnyk Zaporizkoho natsionalnoho universytetu. Seriia: Fizychne vykhovannia i sport. Zaporizhzhia, 1, 5-11. [in Ukrainian]

6. Ivashchenko, O. (2016). Pedahohichnyi kontrol rukhovoi i funktsionalnoi pidhotovlenosti divchat 15-16 rokiv [Pedagogical control of motor and functional readiness of girls aged 15-16]. Teoriia ta metodyka fizychnoho vykhovannia, (3), 36-50. https://doi.org/10.17309/tmfv.2016.3.1171 [in Ukrainian]

7. Krutsevych, T.Yu., Vorobiov, M.I., \& Bezverkhnia, H.V. (2011). Kontrol u fizychnomu vykhovanni ditei, pidlitkiv $i$ molodi [Control in physical education of children, adolescents and youth]. Kyiv : Olimp. 1-ra, 2011, 224. [in Ukrainian]

8. Salnykova, S., Hurenko, O., \& Puzdymir, M. (2017). Dynamika pokaznykiv fizychnoi pidhotovlenosti studentiv VNZ pid vplyvom zaniat z plavannia, lehkoi atletyky ta boksu [Dynamics of indicators of physical fitness of university students under the influence of swimming, athletics and boxing]. Fizychna kultura, sport ta zdorovia natsii. Vinnytsia, 4, 226-231. [in Ukrainian]

9. Beggs, S., Foong, Y.C., Le HCT, Noor, D., WoodBaker, R., \& Walters, J.A.E. (2013). Swimming training for asthma in children and adolescents aged 18 years and under. Cochrane Database Syst. Rev. DOI: 10.1002/14651858.CD009607.pub2.

10. Bergamin, M. et al. (2013). Water-versus land-based exercise in elderly subjects: effects on physical performance and body composition. Clin. Interv. Aging. 8, 1109-1117. DOI: 10.2147/ CIA.S44198.

11. Hruzevych, I., Bohuslavska, V., Kropta, R., Galan, Y., Nakonechnyi, I., \& Pityn, M. (2017). The effectiveness of the endogenous-hypoxic breathing in the physical training of skilled swimmers. Journal of Physical Education and Sport, 17 (3), 1009-1016. DOI: 10.7752/jpes.2017.s3155.

12. Ivanenko, S., Tyshchenko, V., Pityn, M., Hlukhov, I., Drobot, K., Dyadechko, I., Zhuravlov, I., Omelianenko, H., \& Sokolova, O. (2020). Analysis of the indicators of athletes at leading sports schools in swimming. Journal of Physical Education and Sport, 20 (4), 1721-1726. DOI: 10.7752/jpes.2020.04233.

13. Muhamad, T.A., Sattar, H. Abadi, F.H., \& Haron, Z. (2013). The Effect of Swimming Abilityon the Anxiety Levels of Female College Students. Asian Social Science, 9, 15.

14. Pashkevich, S., Kriventsova, I., \& Galicheva, K. (2018). Using Movement Test to Evaluate Effectiveness of Health and Fitness Activities of Students in Higher Education Institutions. Teoriâ Ta Metodika Fizičnogo Vihovannâ, 18 (1), 12-22. DOI: 10.17309/tmfv.2018.1.02.

15. Petrescu, S., Pitigoi, G., \& Păunescu, M. (2014). The Effects of Practicing Swimming on The Psychological Tone in Adulthood, Procedia. Social and Behavioral Sciences, 159, 74-77.

16. Shvets, O., Kovalchuk, A., Bohuslavska V., Hlukhov, I., Pityn, M., \& Khimenes K. (2020). Development of young pupils' physical qualities on the systematic approach basis in the physical education process. SPORT AND SOCIETY Interdisciplinary Journal of Physical Education and Sports. 20, 2. DOI: $10.36836 / 2020 / 2 / 5$. 